\title{
Las redes sociales en el proceso actual de reconstrucción de San Gregorio Atlapulco, Xochimilco, Ciudad de México
}

\section{Social networks in the current process of the reconstruction of San Gregorio Atlapulco, Xochimilco, México City}

\author{
Laura Isabel Romero Castillo* e Itzel Lovera Valencia**
}

Citar este artículo como: Romero Castillo, L.I. y Lovera Valencia, I. (2018). Las redes sociales en el proceso actual de reconstrucción de San Gregorio Atlapulco, Xochimilco, Ciudad de México. Revista Nodo, 13(25), pp. 44-64

\section{Resumen}

Este artículo muestra los principales elementos socio-ambientales que influyen en la presencia de riesgos naturales y antrópicos, así como la vulnerabilidad de distintas zonas geográficas y grupos sociales de la Ciudad de México que han sido históricamente afectados por la recurrencia de sismos e inundaciones. Se identifican los principales problemas en la elaboración del diagnóstico de las afectaciones derivadas de los sismos de 1985 y 2017, especialmente los relacionados con la pérdida de vivienda y a los procesos de merma y contaminación de cuerpos de agua que abastecen a los habitantes de la Ciudad de México. Se describe también las diversas formas de participación de instituciones públicas y sociales en las etapas de emergencia y de reconstrucción de zonas de la ciudad.

El objetivo de este artículo es mostrar el proceso de construcción de redes sociales para el apoyo a damnificados en la Ciudad de México, especial- mente en el pueblo de San Gregorio, Atlapulco, Xochimilco; la participación del sector público, considerando los instrumentos de planeación y las políticas públicas del actual gobierno; la contribución del sector privado para cubrir desde algunas necesidades básicas hasta la construcción de vivienda; la participación de organizaciones sociales existentes y aquellas que surgieron a raíz del sismo, en las que destaca el trabajo de los jóvenes.

Además se desarrolla un análisis comparativo de los efectos de los sismos de septiembre de 1985 y 2018, con el fin de comprender los avances de nuestra sociedad en el desarrollo de capacidades de gestión de recursos, de la organización social en específico, de los avances de conocimientos técnico-científicos y económicos ante las emergencias, que apoyen el proceso de reconstrucción de las zonas afectadas, particularmente en la Ciudad de México. Entre los problemas identificados se encuentra la falta de actualización y aplicación de programas de conservación ambiental y de

Fecha de recibo: 05 de julio de 2018 • Fecha de aceptación: 20 de noviembre de 2018

* Docente investigadora de la Universidad Autónoma Metropolitana unidad Xochimilco, integrante del área de investigación "Espacios Habitables y Medio Ambiente"; Ciudad de México, México, lromero@ymail.com

* Ayudanta de investigación de la Universidad Autónoma Metropolitana unidad Xochimilco, integrante del área de investigación “Espacios Habitables y Medio Ambiente”; Ciudad de México, México, lovera_itzel@yahoo.com.mx 
desarrollo urbano asociados a una mayor vulnerabilidad social, así como la falta de comunicación con los damnificados y especialmente claridad sobre el ejercicio de recursos asignados a la reconstrucción.

Palabras clave: Medio ambiente, Riesgos y vulnerabilidad, Organización social, Políticas públicas.

\section{Abstract}

This paper discusses the main socio-environmental elements that influence the presence of natural and anthropogenic risks, as well as the vulnerability of different geographical areas and social groups of this city, which has been affected repeatedly throughout history by earthquakes and floods. An assessment is given of the deleterious effects resulting from the 1985 and 2017 earthquakes. The main problems are identified, especially as related to housing loss and the processes of depletion and contamination of water bodies that supply the inhabitants of Mexico City. The various forms of participation by public and social institutions are identified as they occurred in the stages of emergency response and reconstruction of affected areas of the city.

The objective of this article is to recount the process of construction of social networks to support victims in Mexico City, in particular in the town of San Gregorio Atlapulco, Xochimilco. Aspects examined include participation by the public sector, taking into account the planning tools and public policies of the current government; the contribution of the private sector, ranging from covering basic needs to constructing housing; and the participation of existing social organizations and new organizations that arose in response to the earthquake, in which the work done by young people is particularly notable.

In addition, the paper gives a comparative analysis of the effects of the September 1985 and 2018 earthquakes, showing the advances in resource management capacity, specifically of social organizations; and advances in technological, scientific and economic knowledge supporting the reconstruction process in the affected areas in response to emergencies, with particular reference to Mexico City. Among the problems identified there exists a deficiency in updating and application of environmental conservation and urban development programs associated with social vulnerability, and a deficiency in communication with the victims, especially in respect to clarity about the spending of funds allocated to reconstruction.

Keywords: Environment, Risks and vulnerability, Social organization, Public policy.

\section{Introducción}

El 19 de septiembre de 2017 se cumplieron 32 años del terremoto de 1985, en el que colapsaron edificaciones de las delegaciones centrales de la Ciudad de México. Desde entonces los simulacros de alerta sísmica, especialmente en las instituciones de educación y lugares de trabajo, han sido la forma de mantener en la memoria la probabilidad de repetición de este fenómeno natural.

Una situación inesperada fue que a los simulacros de "recordatorio" desarrollados a lo largo de la jornada matutina de ese día, le siguió un terremoto de 7.1 grados en la escala de Richter, que afectaron a la Ciudad de México y a los estados de Morelos, Oaxaca y Puebla, donde la incertidumbre fue la constante en escuelas, hospitales y centros de trabajo.

Las mayores afectaciones en la Ciudad de México se presentaron en una zona distinta a la impactada en 1985. En esta ocasión la intensidad del terremoto fue de 8.1 grados, uno menos que el de 2017, pero la cercanía del epicentro provocó que las ondas sísmicas se sintieran con mayor intensidad en áreas del antiguo lago, que ahora son ocupadas por terrenos agrícolas y por poblados rurales (Véase Mapa 1). La razón está en diversas condiciones como la extracción de agua de los mantos acuíferos para abastecer a esta ciudad desde principios del siglo XX, la compactación de suelos arcillosos, especialmente en zonas urbanizadas y 


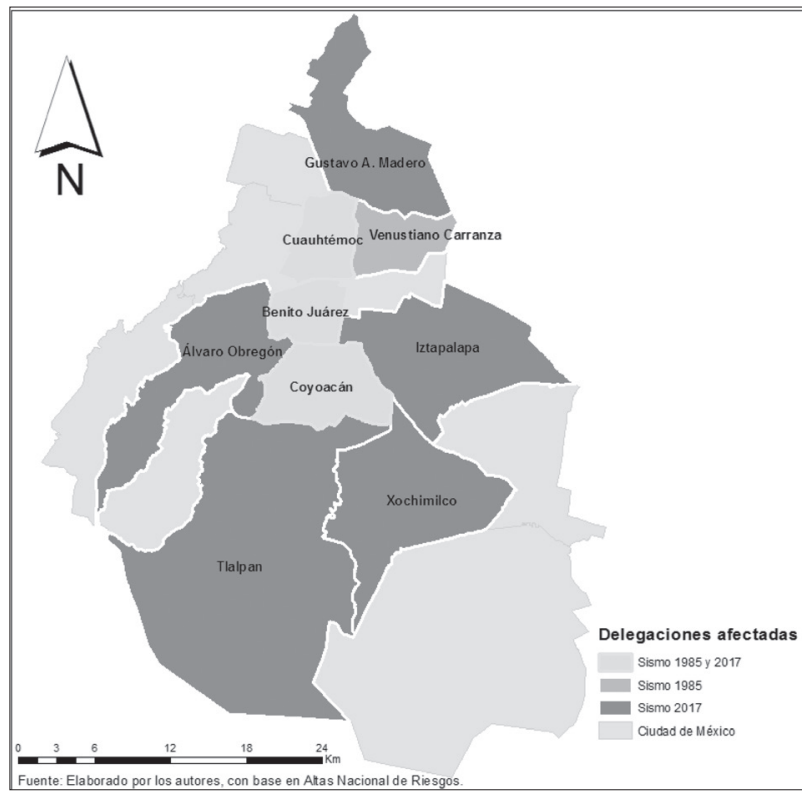

Mapa 1. Delegaciones afectadas por los sismos de septiembre de 1985 y 2017, Ciudad de México. Fuente: Elaboración propia con base en datos INEGI 2017. Estadísticas sobre las afectaciones de los sismos de septiembre de 2017

la existencia de fracturas y grietas formadas en el proceso de enfriamiento de la lava arrojada por el volcán Xitle en los años 50 a.C. y 76 d.C. (Villa, 1997)

Apenas unos días antes de los sismos del 7 y 19 de septiembre, se concluyó la actualización del Atlas de riesgo de la Ciudad de México, elaborado por el Instituto de Geología de la Universidad Nacional Autónoma de México (UNAM) y el Centro Nacional de Prevención de Desastres (Cenapred) que fue creado para contender con los efectos de sismos posteriores a 1985, en el que se difunde información sobre los riesgos naturales y antrópicos, información que está permitiendo establecer su relación con la localización de las edificaciones e infraestructura colapsadas en diferentes partes de la Ciudad.

El trabajo consta de cuatro partes: la primera expone las condiciones de riesgo y vulnerabilidad de las zonas afectadas de la Ciudad de México; la segunda, los rasgos de la organización social ante la emergencia; la tercera, los programas gubernamentales para la reconstrucción; la cuarta presenta conclusiones sobre los aspectos que deberán ser desarrolladas en el ámbito de la política pública nacional, con la evaluación del cumplimiento de la Ley de Reconstrucción.

\section{Antecedentes: sobre las condiciones de riesgo y vulnerabilidad de zonas afectadas de la Ciudad de México}

En la experiencia del sismo de 2017, encontramos un cambio en el uso del lenguaje que sólo percibimos los que vivimos el anterior (hace 32 años): una primera diferencia es la caracterización del fenómeno por el habitante común y los medios de comunicación es decir, el significado del sismo y el terremoto. El concepto de terremoto está en nuestro imaginario como algo que tiene que ver con destrucción y muerte; el sismo nos remite a movimientos tectónicos de menor intensidad que tienen mayor recurrencia en el país. Los geólogos nos dicen que en el epicentro se produce el terremoto, siendo éste el punto en donde se libera la energía acumulada en las diferentes capas de la Tierra, a partir del cual las ondas expansivas o sísmicas se propagan de manera concéntrica especialmente sobre las fallas, por lo que éstas son la principal fuente sísmica. (Keller, 2016, p. 40)

El Atlas nacional de riesgos desarrollado después de 1985, es más accesible para la población a través de internet y de los medios de comunicación tradicionales; en el caso de los riesgos por fenómenos geológicos nos muestra el trazo de las fracturas, grietas y hundimientos que permiten identificar las zonas y población más vulnerables (Véase Mapa 2).

Esa información tendrá que ser incorporada en los programas de planeación ambiental y territorial, que exige la participación de especialistas de otras disciplinas para que formulen escenarios de crecimiento a futuro y el reordenamiento de los asentamientos humanos. Ellos deben considerar las interrelaciones de los riesgos y las condiciones 


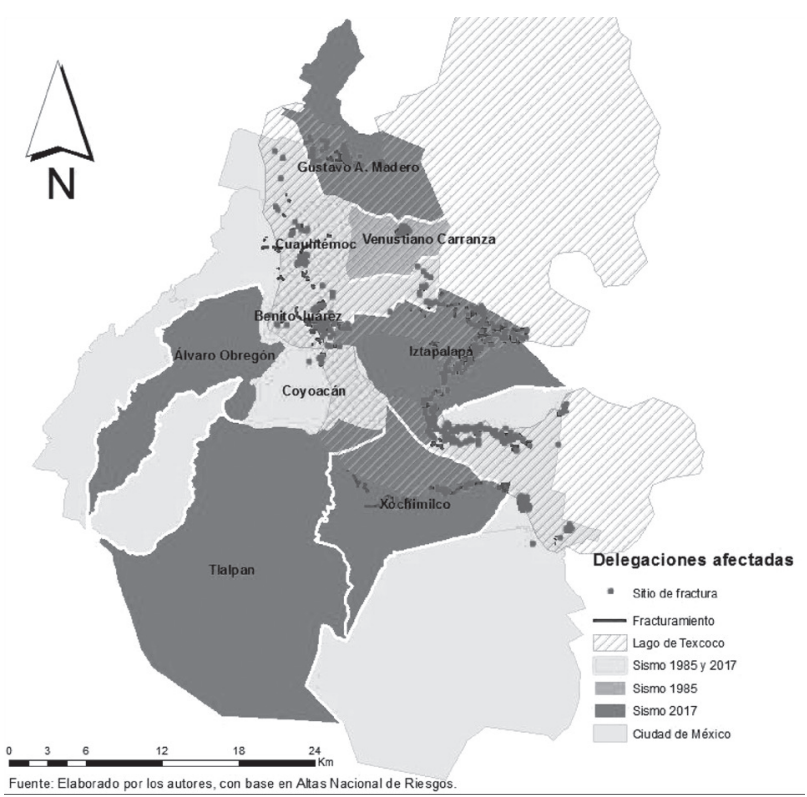

Mapa 2. Vulnerabilidad física en la Ciudad de México. Fuente: Elaboración propia con base en datos INEGI 2017. Estadísticas sobre las afectaciones de los sismos de septiembre de 2017 y el Atlas de Peligros y Riesgos CDMX (Secretaría de Protección Civil, 2017)

de vulnerabilidad de la población, las alteraciones en los ciclos naturales del agua y la reproducción de ecosistemas frágiles al interior de la Cuenca de México como unidad de análisis ambiental, además de las condiciones específicas de la población y las formas de organización social que reduzcan los impactos negativos, con el fin de definir políticas públicas a corto y mediano plazos.

Por esa condición de riesgo natural, la planeación ambiental y territorial así como la construcción de estructuras arquitectónicas e infraestructura, deben responder a la actualización de diagnósticos de condiciones de riesgo y vulnerabilidad, la adecuación de normas y reglamentos, también a los mecanismos de gestión para el cumplimiento de ellas como una obligación de los habitantes y autoridades, ya que de ello dependen la vida y el patrimonio de la población de las zonas en riesgo.

El conocimiento de las condiciones de riesgo naturales y sociales por parte de la población, así como la socialización de información sobre los daños ocurridos por los sismos y sus causas, además de la difusión de los instrumentos de planeación y normativos, son acciones que pueden reducir la vulnerabilidad de los habitantes y la pérdida de vidas y bienes, especialmente de vivienda, equipamiento y centros de trabajo.

Se observa con claridad que el mayor número de hundimientos se han producido entre las orillas del antiguo lago de México y las zonas de tierra firme, es decir en las zonas de transición, ahora se sabe que esta condición amplifica las ondas sísmicas. Los especialistas nos dicen que en el caso de la Ciudad de México si en terreno firme la oscilación dura dos segundos, en la zona de lago puede incrementarse de 10 a 500 veces (Cruz Manuel, 2017, p. 70), dependiendo de la intensidad del terremoto, la distancia y la dirección en la que éste llegue. Lo anterior permite explicar que las áreas más vulnerables son las que conservan cuerpos de agua superficiales, como las del ejido de San Gregorio Atlapulco, Xochimilco, que están rodeadas de áreas urbanizadas y agrícolas; en las cuales además de la afectación en inmuebles se produjo la filtración de aguas superficiales al subsuelo y el rompimiento de los diques que controlan los niveles de agua de la laguna. En el caso de la delegación de Iztapalapa, las altas densidades de población y construcción provocaron mayores daños en las edificaciones de vivienda e infraestructura urbana.

\section{Metodología}

Se realiza con una visión panorámica de análisis comparativo con el fin de identificar, ¿cuáles son los factores que dificultan la atención a los damnificados de los sismos de 2017, que aporten información para prevenir riesgos en un futuro? y se muestran los procesos de organización social en 1985 y 2017 cuyo eje es la colaboración de los distintos sectores sociales en el proceso de reconstrucción y los resultados observados.

El análisis comparativo teje la participación del gobierno local y el de las organizaciones de la sociedad civil en las etapas de emergencia y de reconstrucción, entre los que destacamos su 
influencia sobre las políticas públicas en la elaboración de programas de atención a damnificados, especialmente en los aspectos legales y fuentes de financiamiento públicas, privadas y sociales cuya difusión es limitada. Se destaca la participación de instituciones de educación superior en la elaboración del registro de daños, especialmente en zonas en las que no existe un interés expreso del capital inmobiliario que es el caso de los pueblos originarios del sur de la Ciudad de México, en donde se localiza la población de menores recursos.

Por tratarse de hechos recientes consideramos que la investigación cuali-cuantitativa con la incorporación de los principios del Método Sensible de Vester (Schwanck y Ehnis, 2004) ${ }^{1}$ es adecuada; en una primera etapa el conocimiento de la opinión pública a través de redes sociales y diarios permite sistematizar la percepción del problema desde los damnificados, organizaciones sociales, las autoridades locales y los especialistas que participan en el proceso de reconstrucción; el análisis de dicha triangulación ayuda a identificar los diversos elementos "variables" que hicieron vulnerables a sectores sociales localizados en zonas de mayor riesgo de la ciudad.

En el caso de 1985 la sociedad civil presionó lo suficiente para que se realizara un programa de reconstrucción con la participación de los damnificados en el que colaboré en el diagnóstico de inmuebles afectados en la zona centro de la Ciudad de México, que sirvió como base para la expropiación de predios y la construcción de pequeños conjuntos de vivienda para damnificados.

En el caso de las afectaciones producidas por los sismos de 2017, el gobierno local no realizó un diagnóstico completo de las afectaciones en los sectores más empobrecidos del sur de la Ciudad de México. A lo anterior se suma el sub-ejercicio

1 Es una herramienta bio-cibernética, un método con un enfoque desde los sistemas complejos cuyo objetivo es reducir la complejidad de un conjunto de variables manejable y relevante, que ayuda a la identificación de variables en el sistema y el comportamiento del sistema en su conjunto (Schwanck y Ehnis, 2004). de los recursos públicos asignados a la reconstrucción, la existencia de problemas en el seguimiento técnico y administrativo de las obras desarrolladas, en donde se denuncia la falta de comprobación de gastos y el uso de recursos públicos que no benefician a los damnificados (Sinembargo, 2018).

Dicha percepción permite tener una interpretación más objetiva de la situación actual, retroalimenta los estudio de las condiciones físico ambiental y los riesgos existentes en la biorregión, el trabajo de identificación de daños y definición de proyectos prioritarios de vivienda, equipamiento e infraestructura, con la participación de pobladores de Xochimilco que realizamos desde la Universidad Autónoma Metropolitana-Xochimilco, mismo que puede ser retomado por la nueva administración pública.

\section{Resultados: recuento de daños}

En el ámbito nacional hasta el 19 de octubre de 2017, la información oficial reportó 471 víctimas mortales por los sismos del 7 y 19 de septiembre; 228 se registraron en la Ciudad de México. Se contabilizaron 12 millones de personas afectadas, de las cuales 250,000 quedaron sin vivienda, siendo 5,765 las viviendas dañadas en la Ciudad de México (Ureste, 2017) (Véase Tabla 1).

La información sobre los daños hasta ahora es incierta, ya que no se ha realizado un diagnóstico completo, especialmente en colonias populares de la periferia de la ciudad; a ello se suma que a ocho meses de los sismos, se siguen produciendo e identificando hundimientos diferenciales en los inmuebles, provocados por las ondas sísmicas. Éstas han originado efectos sobre las vialidades y los sistemas de agua y drenaje que provocan oquedades (socavones) en el subsuelo, que no se visualizaron en un primer momento. Otras afectaciones se producen por procesos inadecuados en la demolición de inmuebles, las fugas en la tubería de agua potable y de drenajes, que involucran zonas urbanizadas, a las que se suma la afectación de infraestructura en áreas de producción agrícola. 
Tabla 1. Efectos de los sismos 1985-2017 en la Ciudad de México

\begin{tabular}{|c|c|c|c|}
\hline $\begin{array}{c}\text { Año/ } \\
\text { Factores comparativos }\end{array}$ & $\begin{array}{c}1985 \\
19 \text { y } 20 \text { de septiembre }\end{array}$ & $\begin{array}{c}2017 \\
7 \text { de septiembre }\end{array}$ & $\begin{array}{l}2017 \\
19 \text { de septiembre }\end{array}$ \\
\hline Intensidad en grados Richter & 8.1 & 8.2 & $7.1 *$ \\
\hline Epicentro del terremoto & $\begin{array}{l}\text { Costas de Michoacán, } \\
\text { sobre la costa del Pacífico. }\end{array}$ & $\begin{array}{l}\text { Pijijiapan, Chiapas, } \\
\text { al sur del país. }\end{array}$ & $\begin{array}{l}\text { Límites de los estados de Morelos y Puebla, en } \\
\text { el centro del país. }\end{array}$ \\
\hline Distancia en kilómetros & 350 & 650 & 120 * \\
\hline Hora local & $7: 17$ & 23:49 & $13: 14$ * \\
\hline $\begin{array}{l}\text { Decesos en la Ciudad de } \\
\text { México }\end{array}$ & 10,000 & 0 & $228 *$ \\
\hline $\begin{array}{l}\text { Viviendas dañadas en la } \\
\text { CDMX }\end{array}$ & 698 solicitudes de apoyo & 0 & $\begin{array}{c}\text { 5,765 viviendas con daño estructural. } \\
\text { (60 en Xochimilco). }{ }^{* * * *} \\
\text { (2,185 viviendas dañadas en la delegación } \\
\text { Xochimilco, con diversos apoyos, hasta junio } \\
\left.\text { de } 2018^{* * * * *}\right)\end{array}$ \\
\hline Edificios colapsados CDMX & 770 & 0 & $2,273 * *$ \\
\hline
\end{tabular}

Fuente: *Servicio Sismológico Nacional- UNAM. " Instituto Belisario Domínguez, octubre 2017. *** Secretaría de Desarrollo Agrario, Territorial y Urbano, junio de 2018.

A un mes del sismo de 2017 sólo se registraba un derrumbe en la delegación Xochimilco (Sánchez, 2017); en cuanto a negocios se registraron tiendas de abarrotes, estéticas y papelerías no se reportaron afectaciones en la infraestructura agrícola, por lo que originalmente no se calculó el número de trabajadores afectados, ni valor económico de las afectaciones. Se observa que hasta junio de 2018 en la delegación Xochimilco se han dado, por parte de organismos públicos, apoyos para la reconstrucción de 2,185 viviendas.

\section{La emergencia desde el gobierno local}

\section{Etapa de emergencia 2017s}

La cobertura para sumar esfuerzos entre las instituciones de gobierno y las organizaciones sociales son indispensables para la gestión de recursos federales, locales y los ofrecidos por distintas instituciones privadas nacionales y extranjeras. El 20 de septiembre de 2017 se declaró la Emergencia de todas las Delegaciones de la Ciudad de México y se determinó que el secretario de Protección Civil sería el coordinador del Comité de Emergencias de Protección Civil de la Ciudad de México (Gobierno de la Ciudad de México, 2017a)
Un día después se publicó la Declaratoria de Desastre para la Ciudad de México, con ello se reconoce que las delegaciones políticas afectadas por el sismo del 19 de septiembre no tienen capacidad de recuperación de los daños registrados en "la estructura productiva, la infraestructura vial y de servicios". Esta declaratoria permitiría que el gobierno de ésta ciudad (dependencias, órganos desconcentrados, delegaciones y entidades) atendiera las necesidades básicas de la población, como la protección de la vida, la atención a la salud y la integridad física de las personas, cuyos costos se cubrirían con el Fondo de Atención a Desastres. En ese sentido las instituciones gubernamentales pondrían énfasis en acciones preventivas, al brindar asesoría para el análisis de riesgos, para delimitar las zonas de riesgo. (Gobierno de la Ciudad de México, 2017b)

El martes 26 de septiembre se publicó el decreto para la elaboración del Programa de Reconstrucción de la CDMX y se crea la Comisión para la reconstrucción, recuperación y transformación de la Ciudad de México en una ciudad cada vez más resiliente. En el decreto también se dio instrucción para la creación de la Plataforma Integral CDMX, que concentraría la información sobre 'inmuebles, negocios y personas afectadas', con el fin de tener 
un control y hacer más eficiente la entrega de apoyos; los dictámenes de seguridad estructural serían elaborados por los directores responsables de obra (DRO), quienes definirán la clasificación de daños.

\section{Etapa de emergencia: 1985}

En el caso de los sismos de septiembre de 1985, el gobierno del Distrito Federal, ahora Ciudad de México, fue rebasado por la participación de los habitantes, por lo que las organizaciones sociales lograron contar con representación en la formulación de distintos programas gubernamentales, desde la negociación de quienes debían ser reconocidos como familias damnificadas, hasta quienes permanecerían en la zonas afectadas y las modalidades de solución a las pérdidas parciales y totales de vivienda.

Para ello se creó el Programa Emergente de Vivienda Fase I con el que se atendió a población derechohabiente de instituciones de vivienda; en éste destaca el monto destinado al programa de Renovación Habitacional Popular (274,624.5 millones de pesos) y asignación de vivienda o crédito $(48,800)$. El Programa de Vivienda Emergente Fase II atendió población de escasos recursos, que vivía en vecindades de la zona central de la ciudad, especialmente por el Fondo Nacional de Habitaciones Populares (Fonhapo).

El diagnóstico de afectaciones a inmuebles y familias se realizó por equipos de especialistas a solicitud de la Secretaría de Desarrollo Urbano y Ecología que era la responsable de coordinar las acciones de vivienda del sector público. En aquel año no se contaba con una metodología especial para realizar la evaluación de daños estructurales a inmuebles, por lo que se confió en los conocimientos y experiencia de los distintos grupos de trabajo. Como participante en la elaboración de diagnóstico de zonas afectadas, puedo afirmar que una parte significativa de inmuebles dañados respondió a la falta de mantenimiento de los inmuebles, además de las condiciones de suelo.
Debido a la dificultad para atender a los damnificados, en 1987 se publicó un nuevo decreto por el que se autorizó la instrumentación y ejecución de un programa de adquisición, por parte de los ocupantes, de las viviendas y locales, en inmuebles de más de 10 departamentos; éstos concluyeron los trámites de adquisición con apoyo de Fonhapo hasta 1989.

Una de las conclusiones de la evaluación de la experiencia posterior al sismo de 1985, realizada dos años después por especialistas de la UNAM, fue que se requeriría un análisis multidisciplinario que permitiera "establecer causas y efectos con el propósito de mitigar las consecuencias que puedan tener desastres futuros" (Mecatl, 1987, p. 16).

Consideramos el papel de las organizaciones sociales como uno de los elementos que marcan diferencias en la creación de programas de vivienda para damnificados, por lo que se presenta un análisis comparativo de las experiencias de la participación social en los procesos de reconstrucción de 1985 y 2017, con el fin de identificar los problemas que deberán superarse para educir la vulnerabilidad de los habitantes de la Ciudad de México, con influencia en las políticas públicas del ámbito federal.

Entre los problemas comunes se encuentra la dificultad de identificar en dónde está la ayuda internacional y nacional (El Heraldo, 1985, p. 1) y la falta de información sobre la disposición de los escombros, resultado de la demolición de inmuebles.

\section{Organización social ante la emergencia 2017 y 1985}

Entre los factores que contribuyeron a magnificar los efectos destructivos en la zona central de la Ciudad de México a raíz de los sismos de 1985, se encuentran los siguientes: el cambio de uso de suelo de habitacional a comercial, de habitacional a industrial con lo cual proliferaron las bodegas comerciales y talleres de maquila textil que en algunos casos contaban con sobrecarga, lo que 
significó una condición de mayor riesgo para sus habitantes; el alto hacinamiento en las viviendas con familias de bajos ingresos, muchos de ellos empleados en la zona central. Esta fue la constante en la mayoría de los inmuebles afectados pos su antigüedad y falta de mantenimiento, que en su mayoría se encontraban en renta y con irregularidades sobre la propiedad de los inmuebles.

En ese tiempo la organización para la reconstrucción se direccionó en gran parte por la organización social de los barrios antiguos, que pugnaron por la construcción de vivienda nueva, y se opusieron a ser reubicados en la periferia de la ciudad.

Por lo anterior se determinó un programa de adquisición de predios afectados, que se concretó en un decreto de expropiación de suelo, y la creación de una instancia gubernamental para la elaboración de un programa emergente de vivienda. Los damnificados se organizaron para ser reconocidos oficialmente con el fin de mantenerse en sus antiguos predios, aunque algunos de ellos sí fueron reubicados.

En una primera etapa, la organización social de los damnificados y las organizaciones sociales de apoyo se orientaron a la instalación de albergues para las familias cuyas viviendas se encontraban con daños graves. Un elemento en común fue la gestión de donaciones para cubrir las necesidades básicas, desde agua, alimentos, materiales para la construcción de vivienda provisional y de medicinas. En esta actividad se volcaron los jóvenes de distintas escuelas de educación superior tanto públicas como privadas, que no sólo se concretaron a distribuir alimentos en la Ciudad de México, sino también los llevaron a otros estados de la República.

\section{Participación social: 1985}

En 1985 la atención a la población que quedó sin vivienda fue apoyada por algunas organizaciones laborales, como el caso del Sindicato Único de Trabajadores de la Industria Nuclear (SUTIN), que junto con trabajadores del Sindicato de trabajadores de la Secretaría de Desarrollo Urbano y
Ecología, establecieron en sus instalaciones un albergue en el que se alojaron principalmente damnificados del centro de la ciudad, en donde se garantizó alojamiento, alimentación y talleres para mejorar las condiciones pos-traumáticas. Otros albergues construidos en las zonas afectadas fueron instalados con la solidaridad de vecinos y habitantes de la ciudad.

Uno de los más grandes logros de las organizaciones sociales fue impedir la reubicación de los damnificados del centro de la ciudad en zonas periféricas, lo que obligó al gobierno a decretar la expropiación de los predios dañados y la creación del organismo Renovación Habitacional Popular, que coordinaría la elaboración de un censo para reconocer a las familias damnificadas. La disponibilidad de suelo por la vía de la expropiación permitió la redistribución de las familias en la zona central y facilitó la elaboración de proyectos, la gestión de recursos y la supervisión de obra.

La participación de los damnificados a lo largo de todo el proceso de reconstrucción, desde la identificación de daños y la distribución de las familias en los predios hasta la selección de tipos de vivienda, determinó y facilitó la coordinación con las instancias del gobierno federal y local, esto abrió la posibilidad de llegar a distintos programas, que incluyeron viviendas producidas por organismos paraestatales, así como proyectos desarrollados por organizaciones no gubernamentales y universidades, estos últimos tomaron en cuenta los requerimientos específicos de las familias y las posibilidades de cada uno de los predios.

Originalmente se contempló la conservación y reutilización de inmuebles con algún valor histórico, sin embargo esta decisión fue cancelada, ya que era indispensable simplificar la construcción y supervisión de cada una de las viviendas y, con ello, abatir su costo; de ahí que se optó por la demolición de la mayoría de las edificaciones con algún valor patrimonial y la construcción de obra nueva.

Los programas institucionales promovieron la elaboración del diagnóstico de daños en inmuebles de uso habitacional, de las condiciones de la 
infraestructura y centros de trabajo, así como la identificación de los damnificados se llevó a cabo por diversos despachos con equipos de arquitectos, sociólogos, economistas y planeadores urbanos, cuyo objetivo era contar con un censo de inmuebles dañados y familias involucradas que permitiera diseñar alternativas de vivienda para propietarios e inquilinos: en una primera etapa se atendió a derechohabientes de organismos de vivienda de interés social, especialmente de trabajadores de empresas privadas y para trabajadores al servicio del Estado.

Las organizaciones sociales existentes antes de los sismos habían surgido en un periodo de gran demanda de vivienda en renta por parte de sectores de bajos ingresos en las áreas centrales de la ciudad; así es como se formaron organizaciones de colonos y gremiales en la década de los setenta, que buscaban la conservación del régimen de renta congelada, que persistía en colonias centrales, y demandaban el alto a los desalojos masivos de inquilinos.

En la lucha reivindicativa se mezclaban demandas de vivienda con el apoyo de organizaciones culturales interesadas en lograr la permanencia de los habitantes de bajos ingresos en la zona central, es el caso de la Asociación de Inquilinos que en 1972 aglutinaban a 25 organizaciones gremiales de comerciantes, apoyadas por un grupo cultural singular denominado Tepito Arte Acá, que se opusieron al proyecto de renovación urbana Plan Tepito. Éste se sumaría al más grande proyecto de renovación realizado hasta entonces, con la construcción del conjunto habitacional NonoalcoTlatelolco; por lo anterior, surge la Unión de Vecinos de la Colonia Guerrero en 1974, en la que predominaba la vivienda en renta. De forma simultánea, se crearon asociaciones de residentes de multifamiliares que originalmente eran de trabajadores de distintos gremios, como la Asociación de Residentes del Edificio Gaona, conformada en 1979.

A lo largo de la década de los setenta, el gobierno se enfrentaba a la ocupación irregular de predios en zonas periurbanas, especialmente en áreas natu- rales del poniente del entonces Distrito Federal en donde surgieron otras organizaciones de colonos aglutinadas en la Coordinadora Nacional del Movimiento Urbano Popular (Conamup), constituida a partir de organizaciones de colonos y solicitantes de vivienda, especialmente de la zona poniente de la ciudad. En dicha coordinadora también participaron organizaciones de inquilinos: Unión popular de inquilinos de la colonia Morelos, la Unión popular Martín Carrera, la Unión de inquilinos de Copilco A. C. y la Coordinadora de Asociaciones de Residentes de Tlatelolco, que promovieron la creación de la Coordinadora Inquilinaria del Valle de México.

Después del sismo, surgieron organizaciones sociales que se congregaron en la Coordinadora Única de Damnificados (CUD 1985-1990), que tenían representación en las negociaciones con base en una participación democrática (Serna, 1995, p. 85). Con los antecedentes de participación de organizaciones de colonias populares, el 24 septiembre de 1985 se fundó el Comité Popular de Solidaridad y Reconstrucción (Coposor), con la participación de 32 organizaciones, cuyo propósito era generar un programa de reconstrucción con la participación de las organizaciones populares, que atendiera prioritariamente el problema de la vivienda.

El 5 octubre de 1985 se constituyó la Unión de Vecinos y Damnificados del 19 de septiembre (UVy D) y posteriormente la CUD; esta aglutinó a 40 organizaciones sociales de colonos, inquilinos, de familias que permanecieron en albergues y multifamiliares. Existieron diferentes tipos de organizaciones:

Surgieron Uniones de vecinos conformadas por habitantes de colonias populares en su mayoría de la zona central (de las colonias Guerrero, Pénsil, Tránsito, Morelos, Doctores, Faja de Oro, Martín Carrera, Asturias y Centro). También surgieron organizaciones que buscaron lograr mayor representatividad como los Frentes únicos de colonos localizadas en la zona centro y el primer contorno (Frente único Colonia San Simón, Obrera y Emilio Carranza), en estas dos últimas, fui responsable 
de la identificación de inmuebles dañados y familias damnificadas después de los sismos de 1985, trabajo coordinado en todos los sectores afectados de la ciudad por la Secretaría de Desarrollo Urbano y Ecología, cuya utilidad más importante fue conformar el decreto de Expropiación de predios afectados y su incorporación a los programas de reconstrucción. En áreas peri-centrales surgieron también organizaciones sociales como el Frente de Familias Damnificadas de la colonia Narvarte.

Las zonas centrales que permanecían con rentas congeladas vigentes hasta entonces no reportaban beneficios a sus propietarios, lo que contribuyó a un mayor deterioro de los inmuebles y sus áreas inmediatas generalmente con usos de comercio, bodegas y vivienda en vecindad; sin embargo por su potencial para uso comercial y las presiones del mercado de suelo, surgieron organizaciones sociales De inquilinos de la ciudad (como la Unión de Lucha Inquilinaria del Centro, Unión de inquilinos de lucha: colonia Magdalena Mixhuca, Asociación de Inquilinos 1413 de la colonia Aeronáutica Civil, Unión de Inquilinos y Damnificados del Centro, además del Comité Promotor de la Asociación de Vecinos e Inquilinos de la colonia Álvaro Obregón), que desde los años setenta se oponían al desalojo de sus viviendas (Serna, 1995).

Los sismos de 1985 también causaron grandes afectaciones en áreas De conjuntos habitacionales de alta densidad en renta como el Multifamiliar Juárez construido en 1952 que alojaba población jubilada; otros se encontraban en propiedad privada como la Ciudad Habitacional Nonoalco-Tlatelolco construida en 1964 que se construyó para impulsar la regeneración de la herradura de tugurios del centro de la ciudad, en la que se formaron: la Coordinadora de residentes del ISSSTE de Tlatelolco, el Frente de residentes de Tlatelolco, la Asociación de residentes de Tlatelolco y la Coordinadora de cuartos de azotea de Tlatelolco.

Con los sismos también se fortalecieron organizaciones sociales solicitantes de vivienda como la Coordinadora Nicolás Bravo, el Movimiento de solicitantes de vivienda: Cananea, la Organización de unión de solicitantes y colonos de vivienda popular; el Grupo Azcapotzalco y la Asociación civil A. C. San Miguel Amantla. También se manifestaron demandas por parte de la población alojada en albergues localizados en distintas partes de la ciudad, que en algunos casos permanecieron por años en condiciones de inseguridad y no se les reconoció como damnificados.

La presión de los damnificados para ser reconocidos y atendidos por el gobierno logró, de acuerdo con el primer balance de los programas de reconstrucción, el establecimiento de una "política de arraigo de su población original y el mejoramiento de sus condiciones de vida" (Mecatl, 1987).

Se observa que la población más vulnerable ocupaba inmuebles que se encontraban en renta congelada y aquellos que alojaban actividades de pequeña industria textil, en edificios de uso habitacional sin adecuaciones estructurales y con falta de mantenimiento.

De las edificaciones caídas durante el terremoto, el $60 \%$ estaban bajo régimen de renta congelada. El desastre fue originando en parte la negligencia de las autoridades, que no legislaron a tiempo y se sostuvo como medida populista el Decreto de Congelación de Rentas, lo que ocasionó que los edificios jamás tuvieran mantenimiento" (El Heraldo, 1985).

Entre las críticas se encuentra la falta de distribución de la ayuda internacional y nacional (El Heraldo, 1985, p. 1), paralelamente las organizaciones sociales promovieron la ayuda internacional que en muchos casos fue entregada a los damnificados (Serna, 1995, pp. 77-86), la falta de coordinación en los trabajos de registro de daños provocó que se repitieran más de 3,200 inspecciones (Pradilla, 1996, p. 44).

\section{Participación social: 2017}

La primera acción de la sociedad civil fue ayudar al rescate de las personas que quedaron atrapadas en las edificaciones, así como la recuperación de los cuerpos de aquellos que no sobrevivieron, a pesar de que integrantes del ejército nacional impedían el acceso. 
Paralelamente se establecieron albergues, principalmente con la participación de jóvenes, organizaciones vecinales y de trabajadores que permitieran cubrir las necesidades básicas de techo, seguridad física y alimentación de quienes habían perdido su vivienda y sus fuentes de empleo.

Las afectaciones en la ciudad se dieron en diversas zonas y en general coinciden con los riesgos geológicos de fracturas y hundimientos identificados en el Atlas de riesgos de la Ciudad de México; no hubo una política pública consistente que asegurara el registro de inmuebles afectados que optimizaran la intervención de los sectores público, privado y social. Las instituciones responsabilizadas en atender la emergencia fueron el Instituto para la Seguridad de las Construcciones en el Distrito Federal, la Secretaría de Obras y Servicios, la Secretaría de Desarrollo Urbano y Vivienda y la Secretaría de Protección Civil.

Aunque hubo un sinnúmero de solicitudes de apoyo para el mejoramiento de vivienda y la demolición y renovación de viviendas colapsadas en el sur de la Ciudad de México, el gobierno de la Ciudad le dio mayor prioridad a los edificios de vivienda en altura localizados en las delegaciones centrales, especialmente a edificios que representaban un riesgo para sus habitantes y para las edificaciones vecinas, varios eran muy recientes, en los que se presume que falló la calidad de construcción. El apoyo para demolición no llegó a todos los afectados: a ocho meses del sismo, muchos damnificados no han sido reconocidos ni atendidos.

Después del sismo de 2017, desde el gobierno local se decretó la creación de la "Comisión para la reconstrucción, recuperación y transformación de la Ciudad de México en una CDMX cada vez más resiliente", en el que se definió su composición, atribuciones, programas y recursos asignados.

El Gobierno de la Ciudad de México abrió un programa de apoyo para el pago de renta a los damnificados que duró tres meses, en el proceso se recibieron denuncias por el mal manejo de recursos, especialmente por la inscripción de falsos afectados, por lo que fue suspendido; en mayo de 2018 se "relanzó el programa de apoyo en renta" (Rivera, 2018).

\section{Organizaciones emergentes de la sociedad civil posterior al sismo de 2017}

Uno de los factores que marcaron las formas y el ritmo de la participación social para la reconstrucción de las zonas afectadas fueron los medios de comunicación, especialmente internet, ya que de manera inmediata se pudieron conocer las afectaciones de algunos sitios sin los tradicionales filtros de información.

A diferencia de los trabajos posteriores a los sismos de 1985 en los que la comunicación social e institucional se daba por teléfono fijo, oficios escritos, radio, televisión y telegramas, ahora se dio por teléfonos celulares, whatsApp, correos electrónicos e información almacenada en la nube vía internet.

En la era digital, la participación social e institucional básicamente se estructura en las redes sociales, con el fin de coordinar esfuerzos, ofrecer ayuda, verificar la certeza de la información publicada, así como para la recaudación de fondos nacionales e internacionales en principio relacionados con productos básicos: víveres, agua, ropa e instalación de albergues; posteriormente para la construcción de vivienda temporal (Melgoza, 2017).

\section{Rescate de personas}

El apoyo para el rescate de personas en los inmuebles dañados se dio de forma inmediata con la participación de agrupaciones como Topos A.C., la Brigada Internacional de Rescate (Birta), Topos Tlatelolco-Azteca y Topos Tlatelolco.

\section{Información sobre inmuebles dañados}

En la emergencia se formaron redes interesadas en ofrecer Información sobre inmuebles dañados cuyo objetivo fue conformar una red social entre contactos para corroborar información y necesidades de la población afectada y de los voluntarios 
\#Verificados 19s; con el fin de coordinar la ayuda en inmuebles dañados, se formó la \#RevistaGrieta en donde los ciudadanos subieron fotos de daños en sus viviendas ocasionados por el sismo. También se difundió información sobre bienes inmuebles dañados con \#Salva tu casa conformado por voluntarios especializados en construcción, tales como arquitectos e ingenieros, con la intención de realizar inspecciones de inmuebles dañados y "canalizar los detalles a las autoridades" (Melgoza, 2017).

\section{Apoyo técnico de construcción}

Para ayuda en las demoliciones se ofreció asesoría por arquitectos e ingenieros que recibían vía whatsApp las fotos y videos de daños e inmuebles APL Constructores; también se organizó la construcción de Viviendas emergentes fabricadas con PET, ReConstruir México; y en otro ámbito un grupo de arquitectos impulsó reuniones para analizar la situación y encontrar formas de participación.

\section{Donaciones}

Otras redes sociales permitieron difundir Información sobre donaciones en el ámbito nacional e internacional, entre ellas Cómo ayudar M.X. que reunió la información referente a acopios que incluyó la donación de sangre a la Cruz Roja Mexicana, grupos de rescatistas y la sistematización de todos los contactos de emergencia.

Las aportaciones económicas enviadas en dólares fue iniciativa de This one's for México el cuál entregó el $100 \%$ de las donaciones a la Cruz Roja Mexicana; Mexicanos Community in the UK, comunidad de mexicanos que reside en Reino Unido impulsó la campaña con el fin de recaudar 10,000 euros para ser enviados a México; Los Global Shapers de Ciudad México, Puebla, León y Cuernavaca crearon la campaña "Una mano a México" a través del sitio Donadora. Mx en la que tienen como meta recaudar dos millones de pesos que serían destinados a las personas damnificadas en una primera etapa y posteriormente a trabajos de reconstrucción de la Ciudad de México y los estados de Morelos, Puebla y Tlaxcala.

\section{Oferta de servicios}

La permanencia en albergues es una situación que provoca distintos problemas relacionados enfermedades causadas por variación del clima, falta de servicios, además de la separación de los integrantes de las familias, por lo que es importante la ayuda para contar con un refugio temporal y el acondicionamiento de los albergues.

Con dicho fin se conformó Hogar Terremoto CDMX que a través de Twitter ofreció información a personas que buscan o rentan inmuebles en condiciones solidarias; la base de datos de personas que donan muebles en buen estado para personas que perdieron todo después del sismo a través de Muebletón México. También surgió la red Brigada Lavandería, de personas que apoyan a los damnificados que están en albergues de la ciudad abriendo sus casas para que puedan lavar su ropa. Y también se desarrolló una base de datos para Mascotas damnificadas Gente por la defensa Animal (Gepda), información sobre centros de recepción de perros y gatos damnificados en la Ciudad de México; Mascotas Sismo, a través de Twitter carga información sobre perros y gatos que fueron encontrados en las zonas afectadas.

\section{Identificación de daños en edificaciones y cons- trucción de vivienda temporal}

Colaboraron distintas instituciones como el Centro Operacional de Vivienda y Poblamiento A. C. (Copevi); Taller de Arquitectura Viva (TAVA), promueve proyectos de arquitectura social con diseño ambiental, ha construido vivienda temporal dirigida a población vulnerable, madres solteras $\mathrm{y}$ adultos mayores en Xochimilco, con diversas donaciones, entre las que se encuentra el apoyo de Ambulante, organización de cineastas dedicados a la producción de documentales.

La organización "Comeflores / La casa de la Chinampa" es un proyecto de investigación sobre alimentación y salud que realiza trabajo comu- 
nitario para la mejora de las tierras de cultivo (chinampas) y está constituida en una cooperativa para la compra y repartición de verduras locales.

\section{Gestión de apoyo para el desarrollo de proyectos sociales dirigidos a damnificados:}

Entre los apoyos organizados desde la sociedad civil para la obtención de recursos para la reconstrucción destaca Ambulante, organismo dedicado a producir documentales en diversas ciudades; éste lanzó la campaña internacional de recaudación de dinero "Levantemos México", el objetivo es apoyar a miles de personas afectadas como consecuencia de los sismos de septiembre de 2017.

\section{Participación de universidades en el registro de daños}

A diferencia de 1985 en esta última experiencia ya se cuenta con una metodología orientada a atender la emergencia y para la evaluación de daños estructurales de las edificaciones, que fue desarrollada por el Centro Nacional de Prevención de Desastres (Cenapred); también ya se han definido las responsabilidades de algunas instituciones públicas. A pesar de ello, en el proceso de revisión estructural se pudo constatar que en muchos casos la evaluación preliminar de inmuebles no se realizó por profesionales que supieran identificar las condiciones estructurales de los edificios; esto generó desconfianza en las familias que no recibieron el comprobante de haber sido registrados oficialmente. Por esta situación no pudieron demostrar su estatus como damnificados y, por lo tanto, no lograron concretar la solicitud de apoyos. Los apoyos fueron para el pago de renta por tres meses, gestión de préstamos para mejoramiento y construcción de vivienda nueva con recursos de instituciones públicas y privadas, así como demolición de edificios de vivienda en altura.

Algunos pueblos y colonias de sur y oriente de la ciudad contaron con el apoyo de grupos de profesores y alumnos de instituciones de educa- ción superior, pero la complejidad de trabajo no sólo tuvo que ver con la dimensión de las zonas afectadas, sino con las condiciones políticas y de factibilidad, cuando se declaró oficialmente que la etapa de registro de inmuebles afectados había concluido.

La Facultad de Arquitectura de la UNAM elaboró una plataforma digital para facilitar el registro y acopio de información de inmuebles afectados, lo que permitió que en los meses de octubre y noviembre de 2017 se realizaran inspecciones en distintas zonas de la ciudad, con el fin de verificar el estado de conservación de los inmuebles $\mathrm{y}$, con ello, evitar los riegos para sus habitantes. Fue así como distintas instituciones de educación superior pudieron alimentar la base de datos a distancia: en la Facultad de Arquitectura de la UNAM se habilitó un sistema de revisión estructural con directores responsables de obra (DRO), quienes verificaron la información enviada y avalaron (o no), la opinión de quienes trabajaron en campo.

El siguiente compromiso de las autoridades y profesionistas involucrados en la reconstrucción de las zonas dañadas debe ser el establecimiento de la relación entre los riesgos geológicos y las edificaciones dañadas, con el fin de evaluar las restricciones y posibilidad para la reconstrucción de sus viviendas en el sitio original, o su reubicación. Este trabajo demanda la revisión de zonas en donde no han llegado los profesionistas voluntarios ni las autoridades.

Las condiciones para colaborar en el levantamiento de daños fueron diferentes entre las zonas afectadas: la Universidad Autónoma Metropolitana, Unidad Xochimilco, se propuso contribuir en la identificación de inmuebles dañados y población afectada en su contexto inmediato, que fue la zona sur de la Ciudad de México. 


\section{La Universidad Autónoma Metropolitana Xochimilco y la reconstrucción}

Las universidades públicas en México, como centros de preparación de profesionistas que atienden las necesidades sociales, históricamente han participado en los momentos de contingencia; los efectos de los sismos de septiembre de 2017 nos recordaron que todos somos afectados directa o indirectamente.

El regreso a la Universidad, después del 19 de septiembre, permitió planear las formas de participación en la contingencia, de acuerdo con nuestras disciplinas y grupos de trabajo. Así se generó la convocatoria para la revisión de las edificaciones de la UAM Xochimilco y posteriormente el levantamiento de daños en la zona sur de la Ciudad de México, junto con otras instituciones de nivel superior, coordinadas desde la Facultad de Arquitectura de la Universidad Nacional Autónoma de México.

Aunque de manera casi natural estudiantes y profesores participaron en diversos sitios de la Ciudad de México y de los estados de México y Morelos es a partir del 25 de septiembre que se realizaron reuniones de la comunidad de la División de Ciencias y Artes para el Diseño, para tomar decisiones sobre cómo integrar brigadas para el registro de daños en las edificaciones del sur de la Ciudad de México. El 26 de septiembre comenzamos en algunas zonas de las delegaciones: Coyoacán, Iztapalapa y Xochimilco, con brigadas que se integraron con profesores y alumnos de las licenciaturas en Arquitectura y Planeación Territorial.

Esta organización requirió del intercambio de conocimientos entre los miembros de nuestra División y representantes de la sociedad civil. La respuesta incluyó la comprensión del momento en el que nos encontrábamos y la preparación de estudiantes y profesores para el levantamiento de daños. El 22 de septiembre se organizaron conferencias de especialistas quienes expusieron aspectos sobre el Atlas Nacional de Riesgos, especialmente la vulnerabilidad de grandes zonas del país afectadas por fenómenos tectónicos, además de exponer el método para la evaluación estructural previsto por el Centro Nacional de Prevención de Desastres.

El trabajo desarrollado en San Gregorio Atlapulco es complejo, debido a que se trata de un asentamiento originario del sur de la ciudad, integrado por los Ejidos de Xochimilco y el pueblo de San Gregorio Atlapulco, en donde actualmente se aloja parte importante de la zona lacustre y de la agricultura chinampera, que consta de 2,522.43 hectáreas. Ésta Área Natural Protegida está clasificada como Zona Sujeta a Conservación Ecológica (ZSCE), administrada por la Delegación Xochimilco y normada por la Secretaría del Medio Ambiente. (Secretaría de Medio Ambiente, 2006)

Los pueblos originarios que se localizaban en las orillas de la laguna de agua dulce fueron creando nuevas áreas cultivables sobre la laguna, con el sistema de chinampas que desde la época prehispánica es de gran importancia por la alta producción de alimentos para el consumo regional; las zonas afectadas en 2017 están determinadas por el crecimiento en zonas no aptas para el desarrollo urbano, por lo que se encuentra en suelos de baja resistencia con un alto nivel freático que tiende a inundarse y como se dijo arriba, replica con fuerza las ondas sísmicas.

La organización social a partir de pueblos y barrios es un rasgo de identidad de sus habitantes que se organizan en torno a los santos patronos, reforzados mediante lasos familiares y costumbres tradicionales que incorporan el cultivo de la tierra y la comercialización de sus productos, características que se expresan en la conformación de sus asentamientos. Las mayores transformaciones de Xochimilco, en tiempos modernos, se han dado a raíz de la conurbación de los pueblos a la Ciudad de México, acentuada con la construcción del acueducto que abastece de agua a la Ciudad de México desde principios del siglo XX.

En un primer momento fue difícil colaborar, ya que los habitantes del sitio prefirieron manejar directamente la información sobre los inmuebles 
Tabla 2. La dictaminación de inmuebles afectados y apoyos gubernamentales

\begin{tabular}{|c|c|c|c|}
\hline Clasificación & Características de daños & Acciones que se realizaron & Apoyos y requisitos. \\
\hline Verde & $\begin{array}{l}\text { Inmuebles con daños } \\
\text { superficiales. }\end{array}$ & $\begin{array}{l}\text { Reparación por parte de brigadas } \\
\text { del gobierno capitalino o pago } \\
\text { para la sustitución de vidrios } \\
\text { rotos, arreglo de fisuras y } \\
\text { acabados. }\end{array}$ & $\begin{array}{l}\text { Reparación o pago hasta de ocho mil } \\
\text { pesos. }\end{array}$ \\
\hline Amarillo & $\begin{array}{l}\text { Inmuebles con daños } \\
\text { significativos en condiciones } \\
\text { de habitabilidad. }\end{array}$ & $\begin{array}{l}\text { Ayuda económica por } 3000 \\
\text { pesos para la renta de vivienda. }\end{array}$ & $\begin{array}{l}\text { Reparación sin costo para afectados. } \\
\text { Asociación de desarrolladores inmobilia- } \\
\text { rios (ADI). Créditos para mejoramiento } \\
\text { de vivienda, operados por el Instituto de } \\
\text { Vivienda, Ciudad de México. }\end{array}$ \\
\hline Rojo & $\begin{array}{l}\text { Inmuebles con daños } \\
\text { estructurales, sin condiciones } \\
\text { de habitabilidad. }\end{array}$ & $\begin{array}{l}\text { Apoyo para alquiler y acceso a } \\
\text { créditos a tasas preferenciales } \\
\text { para la adquisición de vivienda. }\end{array}$ & $\begin{array}{l}\text { Realización de un segundo dictamen, por } \\
\text { un corresponsable de seguridad estruc- } \\
\text { tural. Dictamen de reparable o demolido. }\end{array}$ \\
\hline
\end{tabular}

Fuente: elaboración propia con base en el método establecido por el Cenapred

y familias afectadas, para lo cual contaban con un representante por manzana como vía de comunicación con los habitantes. Después de dos semanas sin una respuesta positiva de su parte, iniciamos otra forma de acercamiento, con el apoyo de un profesor prestigiado de la comunidad.

Como equipo de trabajo universitario, integrado por alumnos y profesores de la licenciatura en Arquitectura y del doctorado en Sustentabilidad Ambiental, iniciamos el levantamiento de información con el método establecida por el Cenapred, que consta básicamente de los datos generales del predio y del propietario, la evaluación de daños estructurales y riesgos en el suelo y en las construcciones inmediatas (véase Tabla 2). Encontramos diversos problemas en el levantamiento de información, pues algunas familias afirmaron que, aun cuando se había realizado una revisión por parte de representantes de instituciones públicas especialmente de la Secretaría de Protección Civil, no les habían otorgado ningún documento en el que constatara el nivel de daños de sus viviendas, por lo que se realizaron más de un registro de daños por predio.

Es importante mencionar que en los programas de estudios de las escuelas de arquitectura no existen, hasta el momento, unidades de conocimiento orientadas a la evaluación de daños en edifica- ciones afectadas por diversas causas, que son indispensables en las condiciones de riesgos en las que se encuentran grandes regiones de nuestro país por terremotos, inundaciones, incendios o erupciones volcánicas entre otras. La clasificación se realizó con los criterios de la tabla 2

El registro de daños hasta el momento no se ha concluido y el apoyo institucional a los damnificados ha sido mínimo, si lo comparamos con el programa de reconstrucción de 1985; entre las acciones realizadas destacan la dictaminación del nivel de daños en los inmuebles, el pago de renta para las familias afectadas, el apoyo para la demolición de inmuebles que representan un riesgo, especialmente de edificios de vivienda.

En la segunda etapa, el grupo de profesores y alumnos diseñaron proyectos académico de Vivienda temporal, para lo cual se ofreció en préstamo un terrero de aproximadamente una hectárea, en una zona de pie de monte, en la que se reducía el posible impacto de los sismos, que fueron presentados a la comunidad en enero del presente año. El proyecto profesional lo desarrolló un equipo de trabajo del doctorado de Ciencias y Artes para el Diseño, del área de Sustentabilidad Ambiental, con apoyo del Instituto de Desarrollo Social (Indesol) y otros organismos gubernamentales para la gestión de recursos. 
A partir de esa fecha, con alumnos de la Licenciatura en Arquitectura, se inició el diagnóstico espacial ambiental del pueblo de San Gregorio Atlapulco, en donde se identificaron las problemáticas siguientes: los sistemas de infraestructura, movilidad, vialidad y transporte; estructura territorial y espacial, usos de suelo, sistemas constructivos, estado de conservación de las construcciones, equipamiento rural y urbano, servicios públicos, medio ambiente: ecosistemas de la zona, flora y fauna de los distintos ecosistemas; riesgos, vulnerabilidad e impacto ambiental (Véase Figura 1.). Esta información permite ver los daños en un corte temporal, ya que muchas de las construcciones han sido intervenidas, al menos en sus acabados exteriores

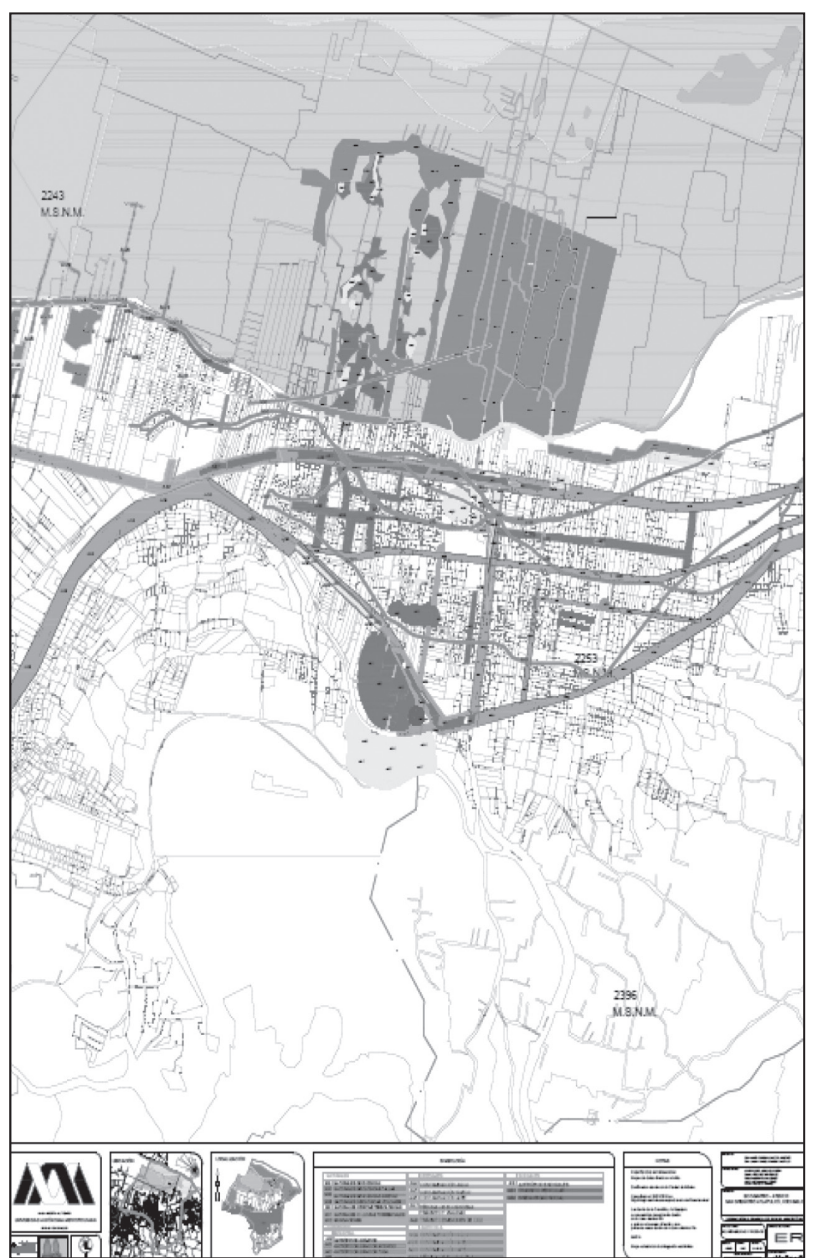

Figura 1. Levantamiento de Riesgos y vulnerabilidad, San Gregorio Atlapulco, Xochimilco, marzo de 2018. Fuente: Alumnos de la Licenciatura en Arquitectura, UAM Xochimilco 2017
Entre los problemas de mayor peso se encuentra la construcción de vivienda en la zona de conservación que amenaza los ecosistemas de humedales frágiles, la contaminación de los cuerpos de agua por descargas de drenaje sin tratamiento, que alteran los ciclos de la flora y fauna acuática; los asentamientos diferenciales de más de 300 edificaciones, por causa de la extracción de agua del subsuelo, para abastecer las necesidades de los habitantes de la Ciudad; los riesgos por la existencia de grietas en el subsuelo que demandan una determinación sobre la reubicación de población a zonas de mayor seguridad, que debería responder a un programa gradual a corto y mediano plazos.

En los daños reportados, no se ha dimensionado las afectaciones de los ambientes naturales por el incremento de contaminación del agua, la afectación de las unidades productivas de las delegaciones que todavía cuentan con agricultura y ganadería, las afectaciones a las redes de comercialización de sus productos, la pérdida de fuentes de empleo, que en muchos casos ha sido informal, pero que de ello dependen muchas familias, especialmente de la producción y comercialización de alimentos tradicionales. También las afectaciones a las actividades turísticas y ecoturísticas debido a la pérdida de niveles en los cuerpos de agua.

Las autoridades gubernamentales han promovido el acercamiento de las instituciones públicas y la Universidad Autónoma Metropolitana para lograr el financiamiento de los proyectos viables. Observamos que la magnitud del problema requiere de un trabajo interdisciplinario y permanente que durará varios años.

A manera de ejemplo se muestra el plano de Riesgos y vulnerabilidad que forma parte del Diagnóstico Físico-ambiental, realizado por alumnos del último año de la licenciatura en Arquitectura de la Universidad Autónoma Metropolitana, en el que se identifica el trazo de grietas geológicas, hundimientos e inundaciones, así como zonas contaminadas por descargas de drenaje 


\section{Programas gubernamentales para la reconstrucción}

Los trabajos para la reconstrucción de la ciudad están coordinados por un consejo conformado por 14 ciudadanos: cinco afectados, seis presidentes de cámaras, colegios y asociaciones, así como tres autoridades de instituciones académicas, entre los que se encuentra el Rector de nuestra Universidad.

La Comisión para la Reconstrucción, Recuperación y Transformación de la Ciudad de México, en una CDMX cada vez más Resiliente (CRRTCDMXR) que fue creada el 1 de diciembre de 2017, y Secretaría de Finanzas de la Ciudad de México a través de la Plataforma CDMX, informan sobre los avances en cuanto al dictamen de inmuebles verificados, el grado de afectación y la cantidad en donativos recibidos por el Gobierno de la Ciudad de México que actualmente asciende a \$ 25, 380,047.00: 5,380,047 aportados por ciudadanos y asignados al FonadenCDMX, mientras que el Grupo Wal-Mart hizo una donación de 20,000,000.00 que se utilizaron en la construcción de al menos 400 viviendas en las delegaciones Tláhuac y Xochimilco (Comisión para la Reconstrucción, 2018). La Secretaría de Desarrollo Urbano y Vivienda coordina el ejercicio de recursos entre los que destacan la asignación presupuestal (Véase Tabla 3).

En el plan de acción aprobado por la CRRTCDMXR destaca por su impacto a corto, mediano y largo plazo la actualización de 16 programas delegacionales de desarrollo urbano, que deberán incorporar los problemas identificados en el Atlas de Riesgos de la Ciudad de México, así como la localización de edificaciones dañadas y población afectada, lo que permitirá contar con un diagnóstico real. La CRRTCDMXR informa que hasta abril de 2017 los dictámenes de inmuebles verificados que se actualizan en tiempo real, contabilizaban 60 derrumbes, 310 demoliciones, 808 inmuebles en Riesgo alto, 519 en Riesgo medio y 2006 en riesgo bajo, además de la asignación presupuestal para la reconstrucción. Es necesario que la información sobre el apoyo a vivienda se publique por delegación, para que los habitantes puedan tener un referente más cercano.

Sobre la asignación de recursos de acuerdo al Artículo 14 de la Ley para la Reconstrucción, Recuperación y Transformación de la Ciudad de México en una cada vez más Resiliente (Gobierno de la Ciudad de México, 2017c), se determinó la aprobación de planes de acción sobre distintos rubros y los organismos responsables de operarlos con los recursos asignados del Fondo para la Atención de Emergencias (Fonden). La asignación de recursos públicos en 2017 fue de 2, 584, 153, 616.99 pesos mexicanos, que se concentrarían en la reconstrucción de infraestructura, vialidades, equipamiento y atención a damnificados y demolición y reconstrucción de vivienda.

El mayor presupuesto se le asigna a la Agencia de Gestión Urbana queestá responsabilizada de realizar obra que principalmente se cubre con servicios de empresas constructoras: vialidades, demoliciones, rehabilitación de escuelas y disposición final del cascajo, este último se está convirtiendo en un gran problema, ya que se está depositando sin autorización en predios baldíos, especialmente en zonas de conservación del sur de la Ciudad de México. La Secretaría de Obras y Servicios de la Ciudad de México es responsable de desarrollar diversos programas, algunos de ellos localizados en las delegaciones de Tláhuac, Xochimilco y Tulyehualco; llama la atención la asignación de escasos recursos para salud y patrimonio cultural de monumentos; así como los limitados recursos asignados a la construcción de vivienda para damnificados de la delegación Xochimilco (Comisión para la Reconstrucción, 2017).

Los cambios entre la asignación de recursos en 2017 y las acciones aprobadas en 2018 se encuentran en la actualización de los Programas de desarrollo urbano de las 16 Alcaldías, ya que esto representaría un incremento en el tiempo de atención a la población asignada; sin embargo esto exige una mayor control de las acciones realizadas, es decir que cubran los requisitos legales y técnicos en su ejecución. 
Tabla 3. Acciones y presupuestos aprobadas para la reconstrucción 2018

\begin{tabular}{|c|c|c|}
\hline $\begin{array}{l}\text { Rubros } \\
\text { y responsables }\end{array}$ & Acciones & $\begin{array}{l}\text { Recursos } \\
\text { (Pesos) }\end{array}$ \\
\hline $\begin{array}{l}\text { la Secretaría de Aguas de la } \\
\text { Ciudad de México }\end{array}$ & $\begin{array}{l}\text { Atenderá obras de reconstrucción de infraestructura de competencia } \\
\text { local de agua y drenaje. }\end{array}$ & $544,296,869.78$ \\
\hline $\begin{array}{l}\text { Secretaría de Obras y } \\
\text { Servicios de la Ciudad de } \\
\text { México. }\end{array}$ & $\begin{array}{l}\text { Diversas acciones entre las que se encuentran: demolición de edificios } \\
\text { ( } 351.5 \mathrm{mp}) \text {, mejoramiento de suelo en Tláhuac y Xochimilco ( } 100 \\
\mathrm{mp}) \text {, rehabilitación de mercados }(120 \mathrm{mp}) \text {, construcción de carretera } \\
\text { Xochimilco-Tulyehualco ( } 50 \mathrm{mp}) \text {, servicios de coordinación técnica y de } \\
\text { campo para demoliciones, reestructuraciones y reparaciones de inmue- } \\
\text { bles afectados en Tláhuac y Xochimilco y proyectos arquitectónicos ( } 36 \\
\mathrm{mp}) \text {, entre otros. }\end{array}$ & $846,829,742.00$ \\
\hline Agencia de Gestión Urbana & $\begin{array}{l}\text { Pavimentación de vialidades primarias y secundarias (807.62 mp), } \\
\text { Demolición de inmuebles ( } 133.75 \mathrm{mp}) \text {, Rehabilitación de escuelas ( } 66.75 \\
\mathrm{mp} \text { ) y carga, transporte y disposición final del cascajo ( } 20 \mathrm{mp}) \text {. }\end{array}$ & $1,028,120,745.87$ \\
\hline $\begin{array}{l}\text { Secretaría de Desarrollo } \\
\text { Social }\end{array}$ & Recuperación de menajes y otros proyectos. & $600,000,000.00$ \\
\hline $\begin{array}{l}\text { Secretaría de Desarrollo } \\
\text { Urbano y Vivienda }\end{array}$ & $\begin{array}{l}\text { Fondos de arranque de reconstrucción de inmuebles de vivienda ( } 140 \\
\mathrm{mp}) \text {, proyectos ejecutivos de reconstrucción }(110 \mathrm{mp}) \text {, aportación para } \\
\text { el cuarto pago a beneficiarios Fonden ( } \$ 88,432,884.00) \text {, equipo de apoyo } \\
\text { para certificación de inmuebles para reconstrucción y otros estudios } \\
(\$ 8,354,296.8) \text { y elaboración de la Ley de Ordenamiento territorial y } \\
\text { desarrollo urbano }(2.5 \mathrm{mp}) \text {. }\end{array}$ & $349,291,180.80$ \\
\hline Secretaría de Cultura & $\begin{array}{l}\text { Programa de restauración del Patrimonio Cultural de Monumentos } \\
\text { Históricos de la Ciudad de México }(\$ 22,831,557.00) \text { y proyectos ejecu- } \\
\text { tivos }(\$ 1,098,625.00)\end{array}$ & $23,930,182.00$ \\
\hline $\begin{array}{l}\text { Secretaría de Educación } \\
\text { CDMX }\end{array}$ & $\begin{array}{l}\text { Convenios, adquisición de materiales y equipamiento para la reconstruc- } \\
\text { ción, rehabilitación y habilitación de escuelas públicas, entre otros. }\end{array}$ & $277,000,000.00$ \\
\hline $\begin{array}{l}\text { Instituto de Verificación } \\
\text { Administrativa de la CDMX }\end{array}$ & Retiro de anuncios de azoteas & $63,000,000.00$ \\
\hline Instituto de Vivienda & $\begin{array}{l}\text { Reforzar acciones de vivienda }(150 \mathrm{mp}) \text {, Financiamiento para la cons- } \\
\text { trucción de } 11 \text { edificios afectados }(500 \mathrm{mp}) \text { y Otorgamiento para ayuda } \\
\text { de renta }(300 \mathrm{mp}) \text {. }\end{array}$ & $950,000,000.00$ \\
\hline $\begin{array}{l}\text { Instituto para la Seguridad } \\
\text { de las Construcciones }\end{array}$ & $\begin{array}{l}\text { Proyecto estructural de rehabilitación }(\$ 278,403,749.75) \text { y Personal de } \\
\text { apoyo para el seguimiento a la reconstrucción y DRO }(\$ 30,645,000.00) \text {. }\end{array}$ & $309,048,749.75$ \\
\hline Secretaría de Salud & Reubicación temporal de dos Centros de Salud. & $2,601,477.06$ \\
\hline Sistema Penitenciario & Reconstrucción de Centros penitenciarios & $387,500,000.00$ \\
\hline Total & & $5,381,618,947.26$ \\
\hline
\end{tabular}

Fuente: Elaboración propia con datos de Plataforma CDMX, Transparencia, Recursos asignados 2018. De acuerdo a los establecido en el Artículo 14 de la Ley de Reconstrucción, publicada en la Gaceta Oficial de la Ciudad de México el 01 de diciembre de 2017.

Consideramos que si bien todos los rubros son importantes en el proceso de reconstrucción, la actualización de programas de desarrollo urbano a mediano y largo plazo debe contar con recursos para su elaboración con el fin de reducir la vulnerabilidad de los habitantes, en donde se consideren los riesgos, se redefinan los límites de densidades de construcción y población, que eviten el desplaza- miento de la población originaria por el incremento del costo del suelo, a raíz de la reconstrucción.

Las familias damnificadas que no han sido apoyadas por instituciones públicas están demoliendo y construyendo sin asesoría ni supervisión técnica, con recursos económicos y mano de obra propios, en muchos casos en predios ubicados en 
zonas próximas o sobre las grietas. Esta situación es recurrente debido a que el apoyo para el pago de renta duró tres meses; las familias comentan que en algunos casos ha sido necesario separar a los miembros de la familia para poder ser recibidos en otras casas.

\section{Sobre las directrices generales de los Programas para la Reconstrucción de la CDMX}

El primer documento que elaboró la Comisión de reconstrucción determinó las directrices generales para el desarrollo de 45 programas para la reconstrucción, de tal forma que deja ver la política pública e atención a damnificados, sus bienes, y la reconstrucción de la ciudad. (Comisión para la Reconstrucción, 2018)

A continuación se citan sólo algunos de los programas de la reconstrucción: una acción masiva y cooperativa del gobierno y la sociedad, subtitulado como Instrumentos básicos para el ejercicio de los derechos: legalidad, participación, diálogo y certeza jurídica (Comisión para la Reconstrucción, 2018, p. 71)

En el Programa número 16 de Estudios de geología, geofísica y geotecnia se expresa el interés de "la reconstrucción se sustente en criterios científicos y sea una guía para la intervención en zonas afectadas por hundimientos y grietas", como responsable único se asigna al Consejo Económico y Social de la Ciudad de México (Comisión para la Reconstrucción, 2018, p. 76). Por su importancia es deseable que se incorpore el Instituto de Geología de la UNAM, no solo por los conocimientos científicos, sino porque cuentan con el antecedente de haber realizado el Atlas de Riesgos de la Ciudad, conjuntamente con el Cenapred.

En el Programa 17 de Atención y tratamiento de grietas, se establece la elaboración de estudios para el mapeo, seguimiento, instrumentación, identificación de predios afectados y restricción en el uso de suelo (Comisión para la Reconstrucción, 2018, p. 76), en el que las instituciones responsables son el Instituto de Ingeniería de la UNAM e Instituto de Seguridad en las Construcciones, lo que requiere su interacción con el Programa 16, referente al desarrollo de los conocimientos científicos.

En el caso del Programa de asistencia técnica para la elaboración de una Política de suelo a favor de la Reconstrucción 18, se enfoca sobre la asistencia de un grupo de expertos de mexicanos y de otros países, destacando el incremento de densidades, incremento del número de viviendas por predio y transferencia de potencialidades, cuyo responsable es el Lincoln Institute.

Esta asignación de responsabilidad es verdaderamente preocupante, ya que se desconoce la experiencia y capacidad de expertos mexicanos y se evidencia la intención de incorporar las zonas afectadas al mercado de suelo (Gil, 2017).

\section{Conclusiones}

A 32 años de distancia, los avances más importantes para prevenir riesgos y reducir la vulnerabilidad de los habitantes de la Ciudad de México se concretan en la creación del Centro Nacional para la Prevención de Desastres (Cenapred), la elaboración del Atlas Nacional de Riesgos, la actualización del Reglamento de construcción para la ciudad que incrementó los criterios de resistencia estructural, la creación del Sistema de alarma sísmica; y una serie de protocolos con responsabilidades económicas, legales y técnicas, asignadas a diversas Secretarías de Gobierno que son poco conocidas por los habitantes de la Ciudad de México.

Entre los aportes del Instituto de Geología de la Universidad Nacional Autónoma de México y del Centro Nacional de Prevención de Desastres se encuentra el Atlas Nacional de Riesgos, cuyo objetivo es que cada estado de país cuente con el suyo, cuyo objetivo es brindar a las autoridades elementos para la planeación territorial y ambiental. En cuanto a los instrumentos de planeación y los métodos para la evaluación de impacto urbano y ambiental, deberán ser actualizados a partir de los hechos recientes. 
En el periodo de emergencia y reconstrucción, se observa una menor integración de la participación política y social con respecto a la experiencia de 1985, en la primera etapa de emergencia de 2017 fue eficiente la intercomunicación a través de internet que hizo accesible la ayuda de la ciudadanía, en la que se advierte la creación de nuevas organizaciones sociales comprometidas con la reconstrucción. Sin embargo en el proceso de reconstrucción se han dado de forma aislada las demandas de los damnificados, lo que influye en que los censos de inmuebles y familias afectadas aún son incompletos, impidiendo el reconocimiento de los damnificados y su incorporación a los diversos programas de construcción de vivienda e infraestructura dañada, especialmente de los sistemas de drenaje y agua potable. Uno de los efectos es la reutilización de predios en los que existen riesgos geológicos, en donde se construye sin asesoría técnica, ante la falta de atención de las instituciones responsables.

En el caso de los pueblos originarios del sur de la Ciudad de México, como el de San Gregorio Atlapulco y Santa María Nativitas, no existe información integrada sobre los avances de la reconstrucción de vivienda e infraestructura; a lo que se suma la falta de atención a las zonas de producción agrícola afectadas. Por lo anterior, es indispensable impulsar el desarrollo de conocimientos científicos y tecnológicos con relación a los efectos de los sismos, así como conocer las diversas formas de respuesta social, con el fin de diseñar instrumentos de prevención y mitigación de riesgos, en los que haya una participación real de los damnificados a lo largo del proceso de reconstrucción, desde la identificación de daños hasta la selección de las mejores soluciones de suelo, vivienda y de fuentes de financiamiento, con políticas públicas que conviertan al gobierno local en un promotor consistente en la definición de una estrategia a corto y mediano plazo y una asignación y supervisión de recursos.

A pesar de que las redes sociales fueron de gran ayuda en la etapa, se observa que la falta de transparencia y veracidad de la información en el proceso de reconstrucción, mantiene a muchos de los damnificados en riesgo permanente, debido a que ante la falta de recursos algunas familias han decidido regresar a sus inmuebles y predios afectados, lo que constituye una política pública irresponsable e ineficiente. En las condiciones actuales es indispensable la colaboración de las instituciones de educación superior con los gobiernos locales y federal, en programas de investigación básica y aplicada, con el fin de generar soluciones adecuadas social y ambientalmente, que optimicen los recursos empleados.

\section{Referencias bibliográficas}

Comisión para la Reconstrucción (31 de diciembre de 2017). Plataforma CDMX. Comisión para la Reconstrucción. Obtenido de: [http:// www.plataforma.cdmx.gob.mx/presupuesto/ recursos-asignado-2017].

Civil, S.D. (24 de septiembre de 2017). Salva tu casa. Obtenido de: [http://www.salvatucasa.mx].

Comisión para la Reconstrucción (5 de mayo de 2018). Programa para la Reconstrucción de la CDMX. Directrices generales. Obtenido de: [htttp://www.reconstrucción.cdmx.gob.mx/ storage/app/uploads/public/5a5/951/9f3/5a595 19f3f047556008364.pdf].

Cruz, M.V. (2017). Los sismos. Una amenaza cotidiana. México: La Caja de Cerillos Ediciones.

El Heraldo (2 de octubre de 1985). Editorial: El 60\% de las edificaciones derrumbadas, de renta cogelada. El Heraldo de México, edición impresa.

Ehnis, S. (2004). Manual de métodos. Modelo de sensitividad Prof. Vester. System tools. St. Gallen: GTZ.

García Cubas, E.C. (2017). Popocatepetl mitos, ciencia y cultura (un cráter en el tiempo). México: Plaza y Valdés.

Gil, O.J. (20 de septiembre de 2017). Proceso.com. Obtenido de: [http:77proceso.com.mx/504119/ en-las-delegaciones-aectadas-lacdmx-reina-laespeculacion-inmobiliaria-ong]. 
Gobierno de la Ciudad de México (2017a). Declaratoria de emergencia con motivo del fenómeno sísmico ocurrido el día diecinueve de septiembre de dosmil diecisiete en la Ciudad de México. Gaceta Oficial de la Ciudad de México, pp. 1-4.

Gobierno de la Ciudad de México (2017b). Declaratoria de Desastre. Gaceta Oficial de la Ciudad de México, pp. 1-4.

Gobierno de la Ciudad de México (2017c). Ley para la Reconstrucción, Recuperación y Transformación de la Ciudad de México en una cada vez más resiliente. Gaceta Oficial de la Ciudad de México, pp. 1-34.

El Heraldo (26 de septiembre de 1985). Entre empresarios. Falta coordinación. El Heraldo de México, p. 1.

Keller, E. (2016). Riesgos naturales. Procesos de la Tierra como riesgos, desastres y catástrofes. Madrid: Pearson Prentice Hall.

Mecatl, J.M. (1987). Casa a los damnificados. Dos años de politica habitacional en la reconstrucción de la Ciudad de México (1985-1987). México: Universidad Nacional Autónoma de México.

Melgoza, A. (27 de septiembre de 2017). 14 asociaciones que apoyan a los afectados por el sismo del 11s. Time Out México. Obtenido de: [http: //www.timeoutmexico.mx/ ciudad-de-mexico/que-hacer/14-asociacionesciviles-que-apoyan-a-los-afectados-porel-sismo-del-19s].

Pradilla, E.C. (1996). Vulnerabilidad, sismos y sociedad en la Ciudad de México 1985 y el futuro. México: UVD 19 de septiembre A. C., Protección Civil DDF.
Rivera, R. (9 de mayo de 2018). Reactivan programa de apoyo a renta para damnificados por sismo del 19S. El Heraldo de México. Obtenido de: [http:// heraldodemexico.com.mx/cdmx/280715/].

Sánchez, M. (25 de octubre de 2017). Instituto Belisario Dominguez. (S. d. República, Ed.) Recuperado el 3 de abril de 2018, de: Instituto Belisario Dominguez [bibliotecadigital.senado. gob.mx/handle/123456789/3721].

Schwanck, \& Ehnis. (2004). Manual de métodos. Modelo de sensitividad Prof. Vester. System tools. St Gallen: GTZ.

Secretaría de Medio Ambiente (4 y 8 de diciembre de 2006). Atención ciudadana. Obtenido de: [httt://sedema.cdmx.gob.mx/programa/suelode-conservacion].

Secretaría de Protección Civil. (29 de septiembre de 2017). Atlas de Peligros y Riesgos CDMX. Obtenido de: [www.atlas.cdmx.gob.mx/zonificacion_sismica.html].

Serna, L. (1995). ¡Aquí nos quedaremos...! testimonios de la Coordinadora Única de Damnificados. México: Unión de Vecinos y Damnificados 19 de septiembre, A.C. y Universidad Iberoamericana A.C.

Sinembargo (10 de mayo de 2018). Le dan a 5 delegaciones de la CdMx millones por el S19, y los gastan en tablets, vestuario, regalos. Obtenido de: [http:www.sinembargo.mx/10-05-2018/341 7090].

Ureste, M. (18 de octubre de 2017). Cifras oficiales del sismo. Animal político.com. Obtenido de: http:www.animalpolitico.com/2017/10/cifrasoficiales-sismo-19s/

Villa, C. (1997). Popocatépetl. Mitos, ciencia y cultura. (un cráter en el tiempo). México: Plaza y Valdés. 